\title{
Mechanical imitation of bidirectional bioadvection in aquatic sediments
}

\author{
G. Y. Matsui * , N. Volkenborn ${ }^{1}$, L. Polerecky ${ }^{2}$, U. Henne ${ }^{3}$, D. S. Wethey ${ }^{1}$, C. R. Lovell' , and S. A. Woodin \\ ${ }^{1}$ Department of Biological Sciences, University of South Carolina, Columbia, SC, 29208, USA \\ ${ }^{2}$ Microsensors Group, Max Planck Institute for Marine Microbiology, Bremen, 28359, Germany \\ ${ }^{3}$ German Aerospace Center, Institute of Aerodynamics and Flow Technology, Göttingen, 37073, Germany
}

\begin{abstract}
Measuring the effects of bioirrigating infauna on sediment properties and geochemistry is often problematic due to the unpredictable nature of the animal activity. This can be overcome by the use of mechanical systems that mimic bioirrigation in a controlled and reproducible manner. A realistic mimic must allow both qualitative and quantitative imitation of the complex infaunal activities, i.e., generate both positive and negative porewater pressure waveforms in a realistic range of amplitudes and frequencies using biologically realistic water volumes. We developed a mechanical irrigation system (Robolug) that meets these criteria and used it to mimic a set of specific hydraulic behaviors of the common lugworm Arenicola marina. The resultant porewater pressure waveforms had realistic shapes and amplitudes and were realized by pumping biologically realistic volumes of water. The porewater flow patterns at depth and at the sediment water interface, induced by bidirectional bioadvection, were comparable to those observed with live lugworms. Additionally, we were able to reproduce the formation of sedimentary cracks, a phenomenon also observed with real lugworms. The Robolug irrigation system is a promising tool for a wide range of biogeochemical and ecological studies, as it (1) allows the exploration of bio-hydraulically induced disruption of sediment integrity and transient geochemical conditions in a controlled and reproducible manner; (2) avoids the uncertainties of animal performance; (3) permits manipulative experimental conditions that could potentially be harmful for organisms or alter their behaviors; and (4) allows for the investigation of energy requirements associated with bio-hydraulic behaviors.
\end{abstract}

Infaunal activities, such as bioirrigation and bioturbation, play an important role in biogeochemical conversion processes in marine sediments (Aller 2001; Lohrer et al. 2004). Benthic infauna increase benthic-pelagic fluxes (MermillodBlondin et al. 2004; Sandwell et al. 2009), affect biogeochemical conversion rates (e.g., Kristensen 1988; Boudreau and Marinelli 1994; Aller 2001; Jahnke 2001, Na et al. 2008), alter benthic habitat characteristics (Thrush et al. 2006; Volkenborn et al. 2007a, 2007b), and drive many inter- and intra-specific interactions among benthic species (Marinelli 1994; Waldbusser and Marinelli 2006). Because of the importance of

*Corresponding author: E-mail: matsui@biol.sc.edu

\section{Acknowledgments}

Supported by the Office of Naval Research (N00014-0310352), NOAA (NA04NOS4780264), NSF (MCB 0237854 and OCE 0928002), and the Max Planck Society. Arthur Illingworth and Allen Frye built the aquaria and modified the peristaltic pump heads. Rob Wheatcroft, Kelly Dorgan, and one anonymous reviewer helped to greatly improve the manuscript.

DOI 10.4319/lom.2011.9.84 infauna for the functioning of benthic systems, it is critical that we understand the underlying processes and the scales of variability and impact.

The use of porewater pressure sensors in benthic research has revealed that the advective transport of porewater in the presence of hydraulically active benthic infauna is neither unidirectional nor of constant magnitude but the result of highly complex sequences of positive and negative, speciesand behavior-specific pressure pulses (Wethey and Woodin 2005; Wethey et al. 2008; Volkenborn et al. 2010). This has been documented for a variety of large benthic species in a wide range of sediment types (Woodin et al. 2010). Thus, a significant part of the biogeochemical cycling in sediments affected by infaunal activity is expected to occur under fluctuating conditions. Numerous microsensor and planar optode measurements have demonstrated that the distribution of porewater solutes in the presence of irrigating infauna is highly variable, both spatially and temporally (Wenzhöfer and Glud 2004; Polerecky et al. 2006; Timmermann et al. 2006; Volkenborn et al. 2010). In muddy sediments, where the exchange of solutes between burrows and the surrounding 
sediment is governed by diffusion, the oscillatory conditions are restricted to the burrow wall and the lumen (Aller 1980; Boudreau and Marinelli 1994; Boudreau 1997). In permeable sediments, where solute transport can be much more efficient due to porewater advection (Huettel and Gust 1992), sediment volumes affected through irregular water injection and transient availability of metabolites by infaunal organisms are much larger (Mermillod-Blondin and Rosenberg 2006; Meysman et al. 2007; Volkenborn et al. 2010).

In general, the oscillatory character of solute availability is expected to have important implications for microbial activity and biogeochemical conversion processes in sediments, including enhancement of organic matter degradation by redox oscillations (Aller 1994; Sun et al. 2002; Franke et al. 2006; Gao et al. 2010) or release of metabolic intermediates (e.g., NO or $\mathrm{N}_{2} \mathrm{O}$ ) by perturbation of chemical reactants (e.g., oxygen or $\mathrm{NO}_{2}^{-}$) (Schreiber et al. 2009; Stief et al. 2009). However, the extent to which geochemical oscillations induced by bioadvection contribute to other processes, such as sulfate reduction, anammox, ammonia oxidation, sulfur oxidation, etc., have not been investigated in detail. The results of Aller (1994), Sun et al. (2002) and Franke et al. (2006) strongly suggest that oscillations on time scales of hours to days drive changes in decomposition rates, whereas those of Schreiber et al. (2009) and Stief et al. (2009) further argue for the importance of short-term oscillations on the scale of minutes. Transient positive and negative hydraulic pulses induced by animal activity may also affect sediment integrity (Volkenborn et al. 2010), but the implications of this phenomenon for the porewater flow patterns and for the energy requirements associated with animal pumping are unknown.

Experimental studies aiming to understand these processes and effects are usually hampered by the fact that the animals exhibit behavior that is often highly variable in both space and time, and can also be affected by the experimental conditions (e.g., geometrical constraints, material properties of surfaces, disturbed sediments; Kristensen 2001). Animal locomotion within aquaria and uncertainties concerning health and behavior make it difficult to replicate experiments and may be one reason for highly variable results. A possible solution to this problem is the replacement of the animal with a mechanical mimic that imitates components of the animal activities in a temporally and spatially controlled and defined way.

Mimics have recently been employed as a promising tool for benthic research to investigate the effects of bioirrigation on biogeochemical cycling ( $\mathrm{Na}$ et al. 2008). However, these mimics induce steady and unidirectional flows and do not adequately reflect the spatio-temporal complexity of bio-hydraulic activities of a living animal. Thus, to better understand the mechanisms behind the aforementioned effects, especially those linked to geochemical oscillations, the mimics must adequately reproduce both spatial and temporal variabilities in geochemical conditions induced by bio-hydraulic activities of a living animal. This is especially important because complex microbial communities may adapt and respond differently to oscillating rather than stationary conditions.

Here, we report on the development of the 'Robolug,' a mechanical, subsurface hydraulic system that allows mimicking of diverse bio-hydraulic activities in aquatic sediments. We provide details of the Robolug design and document the effects on the generated porewater pressure waveforms and porewater flow patterns. According to Darcy's law, porewater pressure distribution in an advective system is a function of the water volume per unit time pumped into or out of the sediment, the sediment volume and geometry over which flow occurs, and the hydraulic conductivity and specific storage of the sediment. All these components are explicitly controlled or accounted for when using our mechanical system. As a proof of concept, we reproduced complex sequences of behavior-specific waveforms that are consistent with the pressure data obtained for live lugworms (Arenicolidae, Polychaeta) in the field and in the lab (Woodin and Wethey 2009). We assessed the authenticity of the Robolug by two-dimensional oxygen imaging and pressure sensors to demonstrate that (1) mimicgenerated porewater pressure waveforms produce porewater flow patterns consistent with those produced by live worms in laboratory experiments and (2) controlled hydraulic pulses are capable of cracking sediments, seen as an abrupt reduction in porewater pressure, a phenomenon frequently observed in porewater pressure recordings from live lugworms.

\section{Materials and procedures}

\section{Sediments}

The top $20 \mathrm{~cm}$ of intertidal sediments were collected from locations within the North Inlet estuary, South Carolina, USA $\left(33^{\circ} 20^{\prime} \mathrm{N}, 79^{\circ} 11^{\prime} \mathrm{W}\right)$. Sediments were maintained at ambient temperature with overlying aerated seawater. Porosity (weight loss after drying) and hydraulic conductivity (constant head method) of each sediment type were measured from 3-5 replicate cores (area: $10 \mathrm{~cm}^{2}$, depth: $10-15 \mathrm{~cm}$ ) prepared in parallel with the experimental aquaria. The hydraulic conductivities of the studied sediments ranged between 0.05 and $1.5 \mathrm{~cm}$ min $^{-1}$, while the porosity was comparable for all sediments (35-45\% volume).

\section{Artificial irrigation system robolug}

The artificial irrigation system consists of two computercontrolled peristaltic pumps that transport water via tubing and injection source into and out of the sediment (Fig. 1). To mimic hydraulic activities of the lugworm Arenicola marina, peristaltic pumps are equipped with Tygon@ tubing with an inner diameter of $1.6 \mathrm{~mm}$ resulting in a volume of $0.21 \mathrm{~mL}$ water being transported with each full rotation of the pump head with either one or two adjacent rollers (Table 1). This is the reported characteristic volume that a 'standard lugworm' pumps per peristaltic stroke (Riisgård et al. 1996). The injection source is a small PVC tube (inner diameter $2.5 \mathrm{~mm}$, covered with a $64 \mu \mathrm{m}$ mesh to prevent suction of particles into 


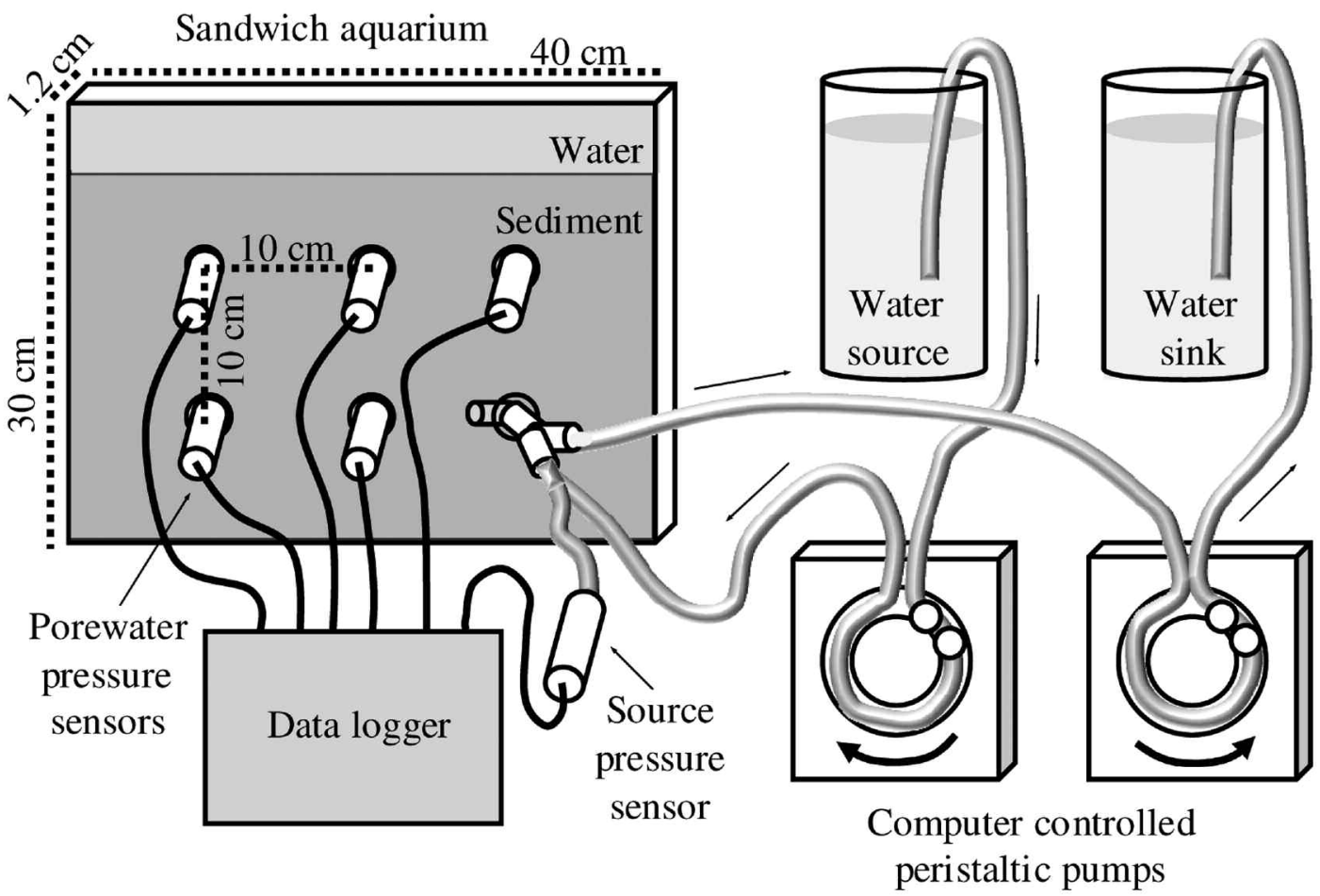

Fig. 1. Schematic diagram of the 'Robolug' mechanical porewater irrigation system. Arrows indicate direction of water flow during forward (left pump) and backward (right pump) pumping. Circles inside peristaltic pumps show the positions of the pump head rollers. The pressure sensor connected to the tubing exiting the aquarium records the source pressure, while the pressure sensors in the sediment record porewater pressures. The water surfaces of the aquarium, the water source, and the water sink were levelled, preventing gravitational water flow when the tubing in the pump heads is not compressed.

the tubing during reverse flow) that resembles the feeding pocket of a lugworm. The injection source is fixed within the aquarium and connected with Tygon tubing via a Y-shaped connector to the peristaltic pumps. Each pump moves water either into or out of the sediment in the experimental chamber in response to computer instructions (Fig. 1). The use of two pumps prevents anoxic porewater from being pumped back into the sediment when the direction of pumping is reversed, thus preventing alteration of solute profiles. The use of two pumps also allows for flexibility in controlling flow rates into and out of sediments by allowing the use of different tubing sizes for different behaviors. To minimize the 'dead' volume that is pumped back and forth during bidirectional hydraulic simulations, the Y-connector was placed immediately outside the aquarium approximately $3 \mathrm{~cm}$ from the injection source, resulting in a dead volume of roughly 0.5 $\mathrm{mL}$. For experiments on the formation of hydraulically induced sedimentary cracks, one of the peristaltic pumps was replaced by a syringe pump (KD Scientific 100) delivering water at constant rates.

The sandwich aquaria were constructed from $1.25 \mathrm{~cm}$ thick plates of acrylic plastic $(40 \times 30 \mathrm{~cm})$ tightly screwed against a gasket of Tygon. Homogenized sediment (20 cm deep) was added and allowed to settle for $\sim 1 \mathrm{~d}$ before measurements. Aerated seawater (approximately $5-6 \mathrm{~cm}$ in depth) overlying the sediment was continuously exchanged at approximately

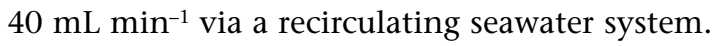

Positive and negative flows were induced using two Masterflex L/S computerized peristaltic pump drives (model 755050(C) Cole-Palmer). The pump software (Masterflex Linkable Instrument Control Software V2.0, catalog no. 7550-74 ColePalmer) allows control of the speed and direction of rotation and programming of complex pumping sequences. Masterflex L/S pump heads (7014-20 and 7016-20@ Cole-Palmer) were used in three configurations: (1) standard peristaltic pump heads, with 3 rollers equidistant from one another; (2) modified pump heads with only a single roller; or (3) modified pump heads with 2 rollers adjacent to one another with a minimal arc separating them (Fig. 2). The use of modified pump heads in combination with different tubing sizes and rotation speeds allowed a wide range of pumping rates and volumes of water injected per peristaltic pulse (Table 1).

\section{Porewater pressure measurements}

Porewater pressures were measured using industrial pressure sensors (Measurement Specialties Inc., model 865 psi, stainless steel diaphragm; see Wethey and Woodin 2005; Wethey et al. 2008). Data were collected using autonomous 8channel 16-bit data loggers (CF2, Persistor Instruments, Inc.) and calibrated as previously described (Wethey and Woodin 2005). The sensors were attached through threaded openings 
Table 1. Parameters for the Robolug used as a lugworm mimic and other configurations tested during the development. These configurations demonstrate the versatility of the system in controlling injection volume and peristaltic frequency. A 'pulse' is one full rotation with either a single or two adjacent rollers, whereas with three equidistant rollers a full rotation generates three pulses. 'ID' is inner diameter of the tubing. L/S 25 tubing requires modified 7016-20 housings with enlarged tubing channels.

Part A. Tubing characteristics, pump head types and rollers used.

\begin{tabular}{|c|c|c|c|c|c|}
\hline Irrigation Type & $\begin{array}{l}\text { Masterflex@ } \\
\text { Pump Head }\end{array}$ & $\begin{array}{l}\text { Masterflex@ } \\
\text { Tubing }\end{array}$ & Tubing ID & Pump Head Rollers & mL per pulse \\
\hline \multirow[t]{2}{*}{ Lugworm mimic } & $7014-20$ & L/S 14 & $1.6 \mathrm{~mm}$ & Single or two adjacent & 0.21 \\
\hline & $7014-20$ & L/S 14 & $1.6 \mathrm{~mm}$ & $\begin{array}{l}\text { Standard unmodified } \\
3 \text { rollers equidistant }\end{array}$ & 0.07 \\
\hline \multirow[t]{4}{*}{ Other configurations } & $7016-20$ & L/S 16 & $3.1 \mathrm{~mm}$ & Single or two adjacent & 0.8 \\
\hline & $7016-20$ & L/S 16 & $3.1 \mathrm{~mm}$ & $\begin{array}{l}\text { Standard unmodified } \\
3 \text { rollers equidistant }\end{array}$ & 0.27 \\
\hline & $\begin{array}{c}7016-20 \\
\text { (channel enlarged) }\end{array}$ & L/S 25 & $4.8 \mathrm{~mm}$ & Single or two adjacent & 2 \\
\hline & $\begin{array}{c}\text { 7016-20 } \\
\text { (channel enlarged) }\end{array}$ & L/S 25 & $4.8 \mathrm{~mm}$ & $\begin{array}{l}\text { Standard unmodified } \\
3 \text { rollers equidistant }\end{array}$ & 0.67 \\
\hline
\end{tabular}

Part B. Robolug pump rates $\left(\mathrm{mL} \mathrm{min}^{-1}\right)$ by configuration*

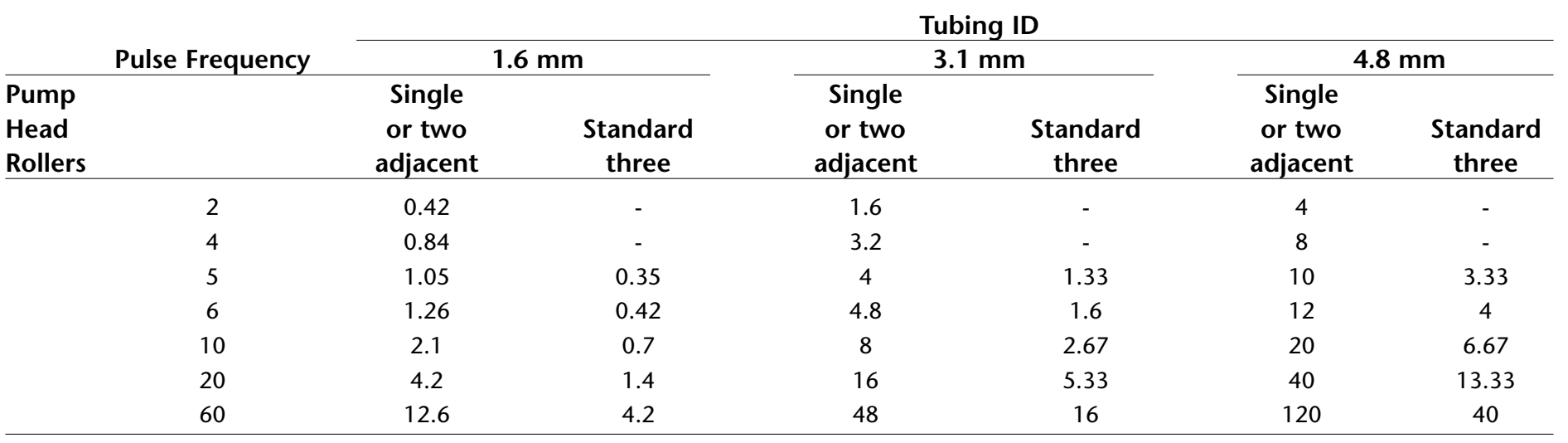

*Pumping rate of the Robolug $\left(\mathrm{mL} \mathrm{min}^{-1}\right)$ as a function of pulse frequency, tubing ID, and pump head roller configuration. All modified pump head trials were run with the following pulse frequencies: $2,3,4,5,6,10,12,15,20,30,60 \mathrm{~min}^{-1}$. Unmodified pump heads with 3 rollers were limited to pulse frequencies greater than 4 , due to minimum rotation constraints of pumps and pump software. Pumping rates are shown for a subset of the pulse frequencies to illustrate their linearity with respect to pulse number with the modified rollers and pump heads.

in one plate of the aquarium and arrayed to collect both vertical and horizontal pressure gradients (Fig. 1). One pressure sensor was connected directly to the tubing exiting the aquarium, thereby detecting the pressure at the injection source, hereafter referred to as source pressure. The measurement of the source pressure allows direct inference on what an animal would be exposed to, i.e., the pressure, applied when pumping fluid at a given rate out of or into the sediment.

Assessment of porewater flow patterns by oxygen imaging

Patterns of porewater flow during Robolug activities were visualized through their effects on oxygen dynamics both within the sediment and in the overlying water. Oxygen sensitive foils (Glud et al. 1996; prepared as described by Precht et al. 2004) were attached to the inner side of the aquarium wall opposite the pressure sensors. Luminescence lifetime images with an effective pixel size of approximately $0.2 \mathrm{~mm}^{2}$ were taken at $30 \mathrm{~s}$ intervals with a luminescence lifetime imaging system (see planar optode imaging below). Oxygen images were calculated from lifetime images using calibration values measured in the anoxic sediment and air-saturated seawater as described in Kühl and Polerecky (2008). Image analysis was done in Matlab (ver. 7, Mathworks; utilities available from authors).

The water, injected into the sediment, was $100 \%$ air saturated. Although with live animals the injected water is significantly depleted in oxygen due to animal respiration and biogeochemical oxygen consumption at the burrow wall, air-saturated water was chosen to maximize the dynamic range of fluorescence quenching by oxygen, and thus, optimize visualization of the porewater flow patterns. Thus, we used oxygen effectively as a reactive tracer, and the oxygen concentrations and the scale of impact need to be interpreted with caution (see "Comments and recommendations"). 

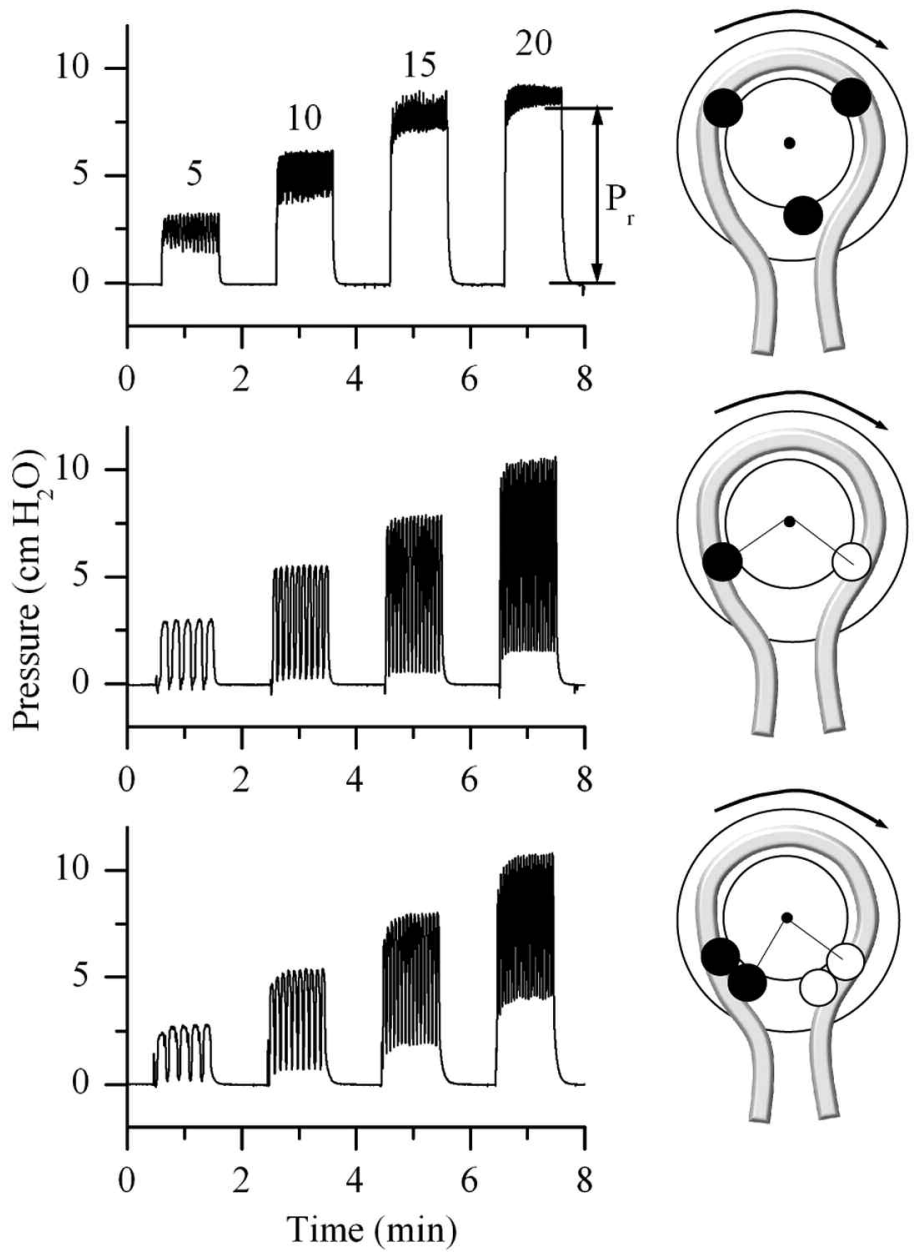

Fig. 2. Roller arrangements in the peristaltic pump heads and resultant porewater pressure waveforms induced by periodic water injections $(0.21$ $\mathrm{mL}$ water pumped with each full rotation) into a sediment with a hydraulic conductivity of $\mathrm{K}=1.0 \mathrm{~cm} \mathrm{~min}{ }^{-1}$. Numbers of full rotations per minute are shown in the upper panel. The hydrostatic pressure baseline was subtracted to allow direct comparison of the different roller arrangements. One or two adjacent rollers yield one porewater pressure pulse per full rotation while three equidistant rollers yield three pulses per full rotation, as indicated by the larger number of pressure peaks. The tubing is not blocked when the rollers pass the tubing insertion points in the pump head, as shown by the black and white colored roller positions. This never occurs in the 3-roller system, resulting in very high residual pressures, $P_{r^{\prime}}$ while the pressure is almost entirely released in the 1-roller set-up at a pulse frequency $<15 \mathrm{~min}^{-1}$. At frequencies $<15 \mathrm{~min}^{-1}$, the two adjacent roller set-up resulted in intermediate residual pressurization, most realistically mimicking peristaltic pumping by lugworms.

\section{Planar optode imaging}

The lifetime imaging system was modified after Holst and Grunwald (2001). It comprised a cooled CCD camera (pco.1600MOD, PCO), a pulse delay generator (T560, Highland Technology), an array of blue-light emitting diodes (LEDs; $\lambda_{\max }=455 \mathrm{~nm}$, LXHL-LR5C, Philips Lumileds) attached to a heat sink $(\sim 5 \times 5 \times 2.5 \mathrm{~cm})$, and a custom-made power supply. The camera accumulates multiple exposures with a programmable modulation time. By using the output of the exposure synchronization of the camera as a trigger for the pulse delay generator and subsequently the LED light pulse, any jitter between the camera exposure time and the preceding light flash can be avoided. The timing parameters were chosen as follows. After the LED pulse of $20 \mu$ s duration and a given delay, $\delta_{i}$, the electronic shutter for camera exposure opens for $\Delta=10 \mu \mathrm{s}$. The delays of $\delta_{1}=1 \mu \mathrm{s}$ and $\delta_{2}=11 \mu \mathrm{s}$ are applied for the accumulation of the first $\left(\mathrm{I}_{1}\right)$ and second $\left(\mathrm{I}_{2}\right)$ intensity window images (gates), respectively, which were acquired sequentially. Summing up all times to $41 \mu$ s for the longest delay reveals the minimum time interval for the accumulations of single exposures. Here an interval of $44 \mu \mathrm{s}$ was chosen, corresponding to a repetition rate of almost $23 \mathrm{kHz}$. Using the first and second intensity window images, the luminescence lifetime image was calculated as $\tau=\Delta / \ln \left(\mathrm{I}_{1} / \mathrm{I}_{2}\right)$ (Holst and Grunwald 2001). The peak current through the LEDs (typically 200-300 mA) and the integration time during which both intensity windows were accumulated (typically 250-1000 ms) were adjusted to optimize image quality. The control of the camera and image acquisition through the IEEE 1394 (firewire) interface, and of the delay pulse generator through the RS232 (serial) interface, were done by a laptop computer using software developed by authors in Borland Delphi and $\mathrm{C}++$.

\section{Irrigation by live lugworms}

Pressure waveforms and porewater flow patterns produced by the Robolug were compared with those recorded during experiments with live lugworms (Arenicola marina) to confirm the system's ability to mimic lugworm hydraulic activity. Hydraulic activities were monitored using time-lapse imagery and classified into four significant behaviors: defecation, burrowing, forward pumping, and reverse pumping (for further detail, see Wethey et al. 2008; Woodin and Wethey 2009; Volkenborn et al. 2010). The associated porewater pressure dynamics and flow patterns were identified from concurrent pressure measurements and oxygen imaging, respectively. Because the aquaria in experiments with live lugworms had identical dimensions as those used in the Robolug measurements, we assumed that any effects on porewater pressure dynamics and porewater flow patterns associated with the geometrical constraints of the aquarium were comparable in both set-ups.

\section{Assessment}

Hydraulic activities of the lugworm $A$. marina are characterized by behavior-specific pressure waveforms (Fig. 3A and 3B). Peristaltic pumping is performed by sequential rhythmic muscle contractions. Forward (tail-to-head) pumping induces characteristic low-magnitude pressure oscillations (Fig. 3B, left) typically with 3-15 pulses per minute (Riisgård et al. 1996; Timmermann et al. 2006; Woodin and Wethey 2009) and occurs more than $60 \%$ of the time (Woodin and Wethey 2009). Occasionally, peristalsis is reversed, and the flow pro- 


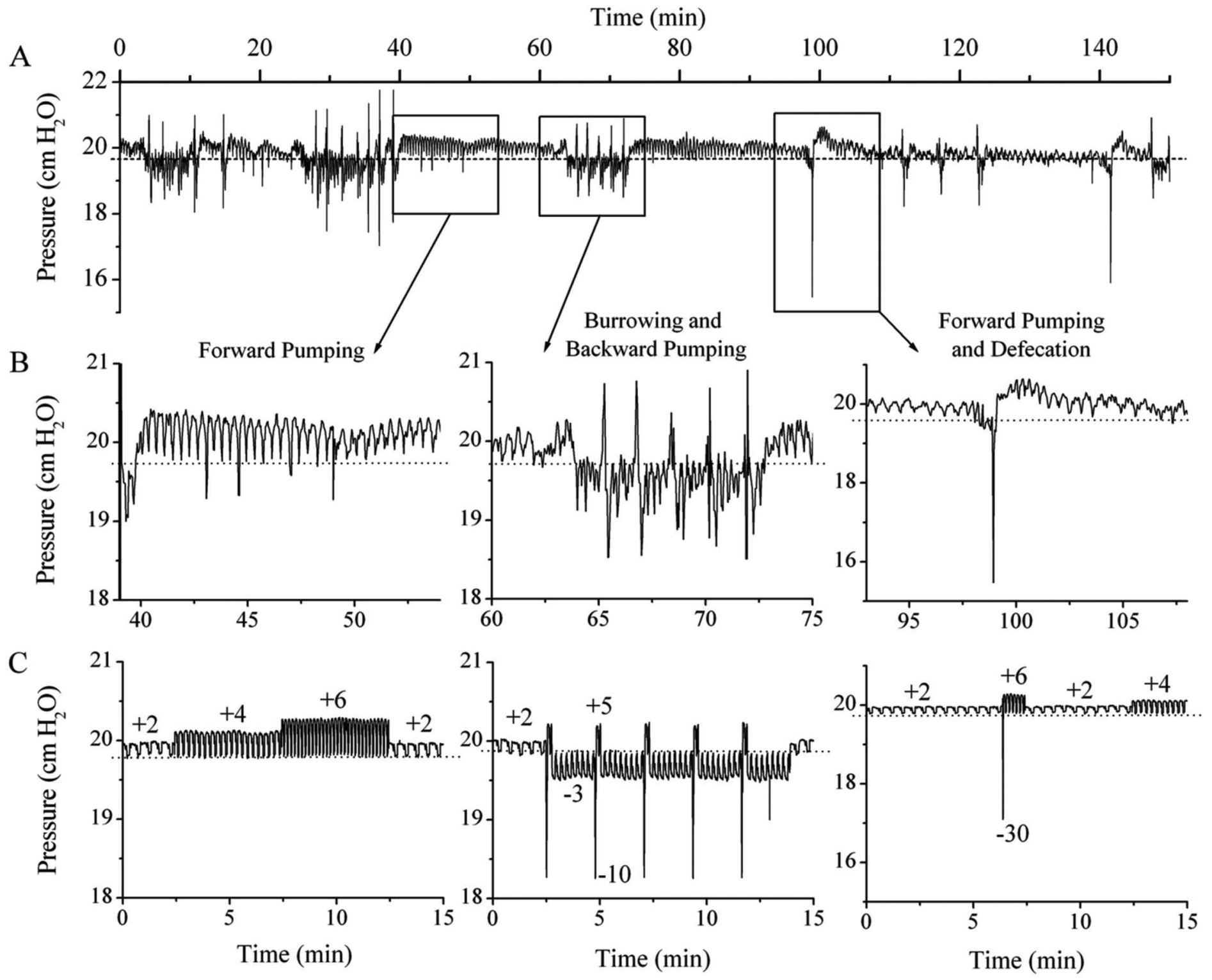

Fig. 3. Porewater pressure waveforms recorded from live Arenicola marina (A and B) and mimicked by the Robolug (C). Panel $B$ is an expanded view of 20 min intervals of panel $A$ as indicated, and illustrates the specific pressure waveforms for forward pumping, burrowing, and defecation. Dotted lines indicate the hydrostatic baseline pressure. Measurements in all cases were done in sediments with hydraulic conductivity of $\mathrm{K}=1.5 \mathrm{~cm}$ min ${ }^{-1}$. Shown are porewater pressure data that were recorded by a sensor located $6 \mathrm{~cm}$ from the injection source (Robolug), whereas the distance between the sensor and the lugworm varied between 5 and $10 \mathrm{~cm}$. The number of rotations per minute (each rotation injecting $0.21 \mathrm{~mL}$ water using the 2 adjacent roller configuration) and direction of rotation (positive for forward pumping, negative for backward pumping) applied in the Robolug simulation are adjacent to each sequence in panel $C$.

ceeds in a head-to-tail direction (Wells 1953; Krueger 1964; Woodin and Wethey 2009), forcing water out of the sediment through the worm's tail-shaft and pulling overlying water into the sediment over the sediment-water interface (Volkenborn et al. 2010). Burrowing is characterized by relatively small negative pressure oscillations interspersed with approximately 25-fold larger positive and negative pressure transients (Fig. 3B, center), and occurs roughly $12 \%$ and $29 \%$ of the time for Arenicola marina and Abarenicola pacifia, respectively (Woodin and Wethey 2009). Defecations are associated with a large neg- ative pulse often followed by high frequency positive pulses (Fig. 3B, right). Defecations occur with great regularity (Wells 1945) but are of short duration and account for only $4-7 \%$ of individuals' time expenditures (Woodin and Wethey 2009).

A challenge in mimicking these hydraulic behaviors for the given tubing diameter was to find the most suitable arrangement of the rollers in the pump heads of the peristaltic pumps. Standard pump heads are equipped with 3 equally spaced rollers. In this configuration, the tubing is effectively always closed (because a roller is always pressing against the 
tubing) and the pressure can decay solely through interstitial water flow. Even in quite permeable sediments (e.g., $\mathrm{K}=1.0$ $\mathrm{cm} \mathrm{min}^{-1}$ ) and at low rotation speeds (e.g., 5 RPM), the 3 roller set-up induced considerable residual pressures $\left(\mathrm{P}_{\mathrm{r}}\right)$ (Fig. 2, upper panel). The dynamic range of porewater pressures for peristaltic pumping at 10 RPM was just a third of the total pressure. In contrast, with live worms, the dynamic range of the pressure waveforms is typically equal to or larger than the residual portion of the pressure waveform in such permeable sediments (Fig. 3), indicating that live lugworms are not capable of perfectly blocking their burrows. Loss of pressure occurs when a peristaltic wave dissipates at the front end of the worm, opening a less pressurized compartment of the burrow in front of the subsequent peristaltic wave front. To allow for such a partial pressure release, we applied a 1-roller pump head in which the tubing was effectively open for $40 \%$ of each pump head rotation (the period when the roller was not squeezing the tubing). This, however, resulted in marginal $P_{r}$ build-up at pumping frequencies characteristic of lugworm peristalsis. For example, when pumping at $10 \mathrm{RPM}$, the relative contribution of the residual pressure $(0.2 \mathrm{~cm})$ to the total pressure $(5.5 \mathrm{~cm})$ was less than $5 \%$ (Fig. 2).

The best arrangement comprised a pump head with 2 adjacent rollers, in which the interval when the tubing is effectively open during a rotation was reduced to $23 \%$ (Fig. 2, lower panel). This resulted in residual porewater pressurization of $0.15 \mathrm{~cm}$ at 5 pulses $\mathrm{min}^{-1}$ and of $0.7 \mathrm{~cm}$ at 10 pulses $\mathrm{min}^{-1}$, with a $13 \%$ relative contribution of the residual pressure to the total pressure at $10 \mathrm{RPM}$. This is comparable to what we have detected with live lugworms in similar sediment types (hydraulic conductivity of $1.0 \mathrm{~cm} \mathrm{~min}-1$ ). Additionally, this configuration was optimal with respect to the number of pulses generated per rotation. While each pump head rotation resulted in three water injection pulses per rotation for the 3roller configuration, the 2-adjacent-roller configuration yielded one pulse per rotation (Table 1; compare top and bottom panels in Fig. 2). Thus, given the minimal rotation speed of 1.7 RPM for most standard peristaltic pumps without gear adjustments, the latter configuration is preferable for mimicking lugworm peristalsis at typical rates of 3-15 pulses $\mathrm{min}^{-1}$. The final consideration was the size of the water flow volume error and the difficulty in maintaining the zero static load with the 1-roller versus the 2-roller setup. A critical concern is control of gravity-induced forward or backflow in the system due to failure to level precisely the water sources and sinks of the system. With the 1-roller setup the tubing is open for long periods, so even small differences in water heights between the source tank and the aquarium generate large gravitational flow errors. The 2-roller setup minimizes this concern.

\section{Robolug as a lugworm mimic}

All behavior-specific porewater pressure waveforms observed with live lugworms were successfully simulated by the Robolug pumping at controlled and biologically realistic flow rates and directions (Fig. 3C). Good quantitative agree- ment was reached for the amplitudes of the pressure pulses, e.g., for sediment with hydraulic conductivity of $1.5 \mathrm{~cm} \mathrm{~min}^{-1}$ and approximately $10 \mathrm{~cm}$ source-sensor distance, the amplitudes did not exceed $1 \mathrm{~cm}$ of water during forward and backward pumping, and reached between $1-3 \mathrm{~cm}$ of water during burrowing and more than $3 \mathrm{~cm}$ of water during defecations (compare Figs. 3B and 3C). This quantitative comparison was important because experimental conditions were similar for both the Robolug and live lugworm measurements (identical aquarium geometries, similar sediment hydraulic conductivities, comparable distances between the water injection source or animal and the pressure sensor).

Good agreement was also achieved with respect to the residual pressurization of the sediment and dynamic range of pressure oscillations in sediments of different hydraulic conductivities. Porewater pressure decay through interstitial porewater flow is governed by the hydraulic conductivity and storage capacity of the bulk sediment. It also depends on the degree to which the lugworm body forms a hydraulic seal against the burrow wall, as well as the effective hydraulic conductivity of the burrow itself. Incomplete porewater pressure decay toward the hydrostatic baseline before the next hydraulic pulse is characteristic of forward peristaltic pumping by live worms in intermediate and low permeability sediments, but not in high permeability sediments (Wethey and Woodin 2005; Volkenborn et al. 2010). The Robolug with partial pressure release in the 2-adjacent roller set-up and pumping at biologically realistic rates and pulse frequencies did not cause detectable residual pressurization of highly permeable sediment (Fig. 3; $\mathrm{K}=1.5 \mathrm{~cm} \mathrm{~min}^{-1}$ ). Moderate residual pressurization was detected at intermediate permeabilities (Fig. 4; $\mathrm{K}=0.33 \mathrm{~cm} \mathrm{~min}^{-1}$ ) and high residual pressurization at low permeabilities (Fig. 5; $\mathrm{K}=0.05 \mathrm{~cm} \mathrm{~min}^{-1}$ ). Because of the complex interplay of physical and biological factors, the agreement of the quantitative relationship between residual and dynamic sediment pressurization induced by live lugworms and the Robolug was considered as satisfactory.

Activities of live Arenicola marina (Wethey et al. 2008; Volkenborn et al. 2010) and of the Robolug resulted in comparable porewater flow patterns for each type of behavior, as qualitatively illustrated by oxygen imaging (Fig. 4). Forward pumping by the Robolug resulted in transport of oxygenated water into sediment surrounding the injection pocket, which was detected by the optode as an increase in the area of oxygenated sediment at depth (Fig. 4D, e.g., minutes 3-8, 32-38, 79-83). The expansion of the oxygenated area during constant peristaltic pumping gradually slowed down and virtually stopped when the transport of oxygen in the porewater by bioadvection and diffusion was balanced by the sedimentary oxygen consumption due to bacterial activity and oxidation of reduced compounds (Fig. 4D, minutes 95-105). Higher pumping rates resulted in more pronounced sediment oxygenation at depth plus an intensive outflow of anoxic water across the sediment-water interface, the latter detected by the 


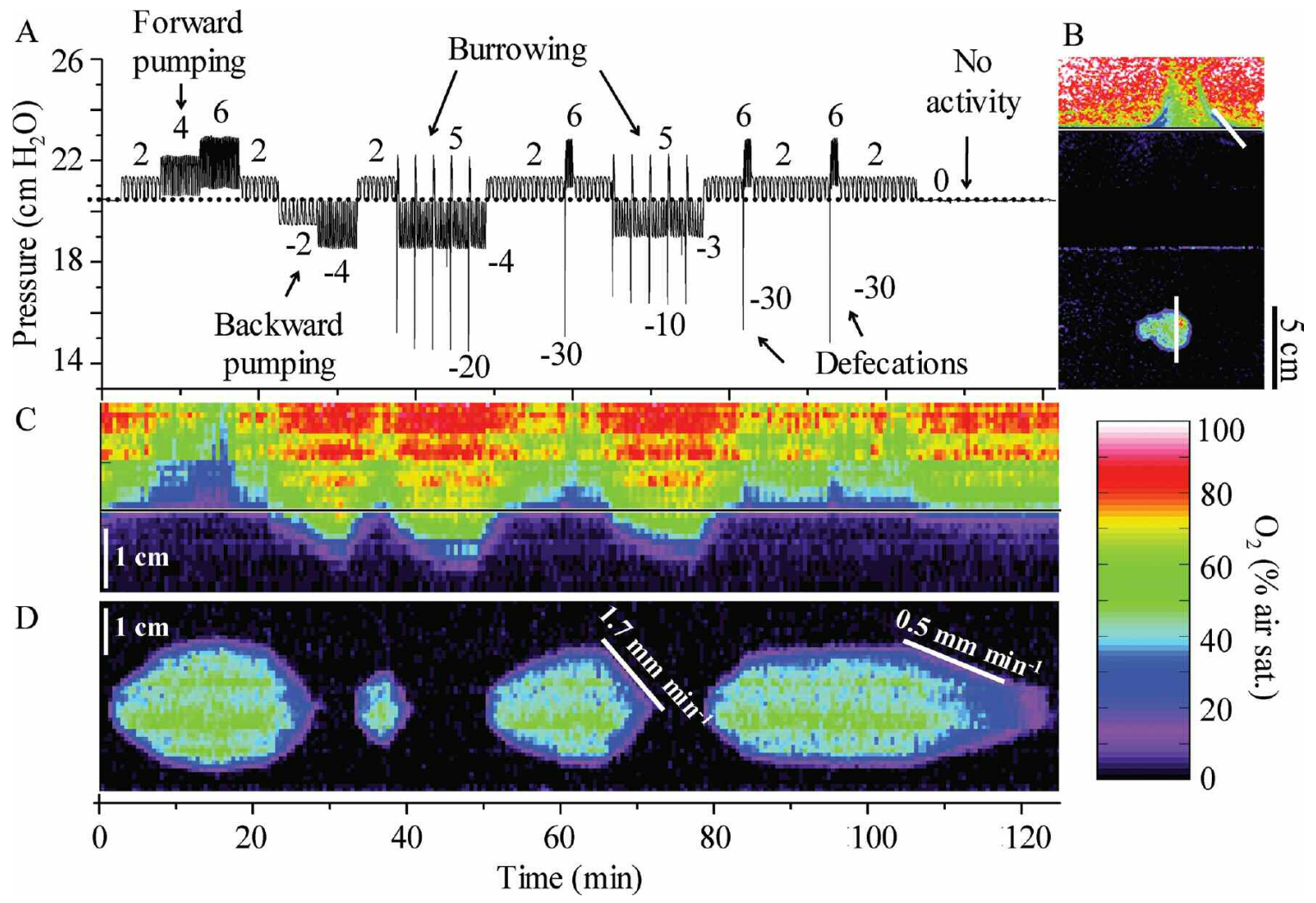

Fig. 4. Hydraulic activities of the Robolug on related bidirectional porewater flow patterns as revealed by time-lapse planar optode imaging of oxygen. Hydraulic conductivity of the sediment was $0.33 \mathrm{~cm} \mathrm{~min}^{-1}$. (A) Pressure recordings from Robolug series simulating forward and backward pumping, burrowing, defecation, and no activity (RPM given as numbers, each rotation delivered $0.2 \mathrm{~mL} \mathrm{H}_{2} 0$; dotted line indicates hydrostatic baseline pressure). (B) Snapshot of the two-dimensional oxygen distribution during intensive forward pumping (at time $t=15$ min). (C-D) Synchronous time series of oxygen concentrations along a profile across the sediment-water interface (C) and in the deep sediment (D) associated with sediment pressurization shown in panel A. Gray horizontal line in C indicates the sediment surface; the profile positions are shown as white bars in panel B. Numbers in panel D represent the rates of spatial progression of the oxic/anoxic front induced by backward pumping during burrowing (minutes 65 to 73 ) and the spatial progression of the front associated solely with chemical and biological oxygen consumption during periods of Robolug inactivity (minutes 105 to 117 ). Note that due to injection of $100 \%$ air saturated water the oxygen concentrations in the deep sediment are higher than those typically observed with live worms

optode through the simultaneous emergence of suboxic plumes above the sediment surface (Fig. 4C, minutes 9-19). When pumping by the Robolug was stopped, the suboxic plumes above the sediment surface collapsed, and the area of oxygenated sediment at depth decreased at a moderate rate as a result of sedimentary oxygen consumption (Fig. 4D, minutes 105-120). During backward pumping, burrowing, or negative pressure pulses, porewater was advected toward the injection pocket, resulting in the transport of oxic overlying water through the sediment water interface and into surficial sediments. Furthermore, if the sediment at depth was previously oxygenated, the volume of this oxygenated sediment was rapidly reduced due to advective flow of anoxic porewater toward the injection pocket in addition to the sedimentary oxygen consumption (Fig. 4C and 4D, minutes 22-29, 65-73).

\section{Sediment cracking}

In porewater pressure records from live lugworms in the field and laboratory, we frequently observed abrupt pressure reductions, especially in sediments of low hydraulic conductivities (Fig. 5A). These did not correspond to periods of back- ward pumping (compare with Fig. 3B) but rather they followed periods of forward pumping during which high positive residual pressure built up in the porewater (Fig. 5A: note the hydrostatic baseline). Because there was a correlation between the drop in pressure and movement of sediment particles, we hypothesized that this phenomenon of abrupt pressure reductions was due to the formation of sediment cracks (i.e., sediment regions with locally increased hydraulic conductivity, putative macropores).

We tested this hypothesis with the Robolug by pumping water at increasing rotation speeds (2-16 RPM) with the 2 adjacent roller set-up into a low permeability sediment $(\mathrm{K}=$ $0.05 \mathrm{~cm} \mathrm{~min}^{-1}$ ) while monitoring porewater and source pressures (Fig. 5). Porewater pressure recordings clearly indicated a significant pressure drop when the pressure fluctuations, superimposed on the residual pressure, reached some critical value (Fig. 5B-C; minutes 20, 30, 70). Because the pumping rate of the Robolug remained constant during the entire episode, the pressure change must have been caused by local alteration of the hydraulic conductivity, i.e., formation of a 

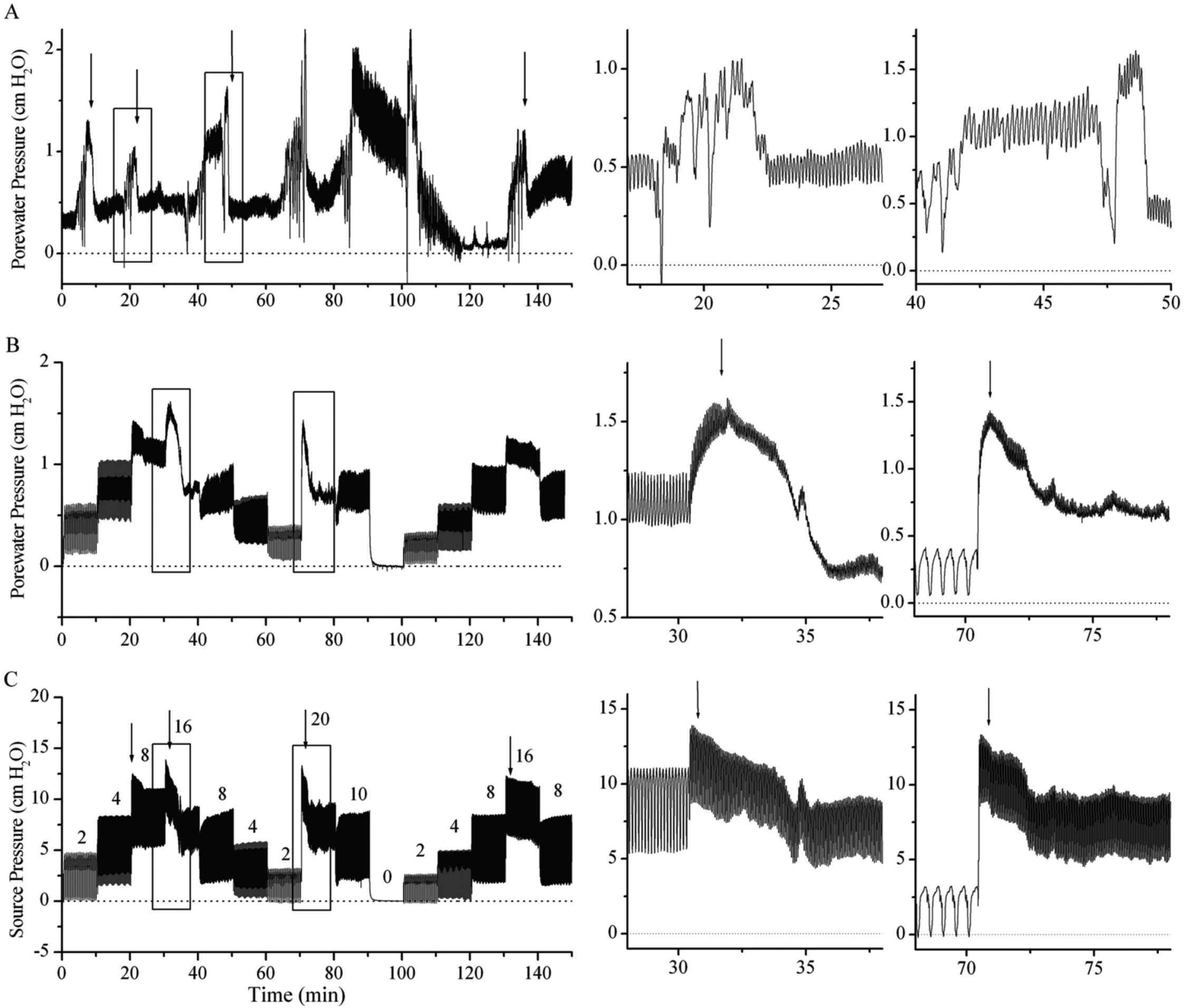

Fig. 5. Porewater pressure waveforms associated with hydraulic cracking of the sediment by a live lugworm (A) and the Robolug (B and C). The righthand panels show enlarged pressure records that are marked with a box in the longer time series on the left. The pressure axis scaling has been adjusted so that hydrostatic baseline pressure (dotted line) is at 0 . Numbers above the pressure record in part $C$ correspond to rotations min ${ }^{-1}$ of the peristaltic pump heads. Part B shows porewater pressures in the sediment, whereas part $C$ is the synchronous record of the source pressure. Arrows denote points at which hydraulic cracking was induced $(\mathrm{A}$ and $\mathrm{C}$ ). The Robolug measurements were done in sediment with a hydraulic conductivity of $\mathrm{K}=0.05 \mathrm{~cm}$ $\mathrm{min}^{-1}$. The hydraulic conductivity of the lugworm sediment was not estimated, but field measurements for that site had a hydraulic conductivity of $\mathrm{K}<$ $0.5 \mathrm{~cm} \mathrm{~min}^{-1}$. During the Robolug simulation, the average pumping rate was $100 \mathrm{~mL} \mathrm{~h}^{-1}$, a realistic pumping rate of live lugworms.

crack. For a given pumping rate, the porewater and source pressures remained approximately $30 \%$ to $40 \%$ lower after this event (compare, e.g., pressures at 4 RPM in time intervals 110-120 min and 10-20 min; Fig. 5B), indicating an irreversible change in the local hydraulic conductivity. It should be noted that these cracks differ from those described by Dorgan et al. (2006) for muds in that they result from the rapid injection of fluid at rates that exceed the hydraulic conductiv- ity of the bulk sediment.

Although the above described experiment established that sediment cracks are formed when the porewater pressure exceeds a critical value, the required pressure raise was achieved under conditions that are not typical of lugworm peristalsis. For example, we used 8-16 water injection pulses per minute (Fig. 5B-C), which are at the higher end of frequencies performed by lugworms (Riisgård et al. 1996; Tim- 
mermann et al. 2006). With live animals, abrupt drops in residual pressure are typically not associated with an increased pulse rate but rather follow one or more large pressure pulses, such as those induced during burrowing bouts (Woodin and Wethey 2009; see also Fig. 5A, interval 19.5-20.5 min).

We tested the importance of these larger pressure pulses on sediment integrity by combining pulsed injections by the Robolug with continuous water injection at a constant rate achieved by a syringe pump. At biologically realistic rates of 1 $\mathrm{mL} \mathrm{min}^{-1}$, constant pumping resulted in the build-up of steady-state source and porewater pressures. The addition of hydraulic pulses to the continuous water pumping caused abrupt pressure drops at unchanged pumping rates, indicating changes in the sediments resistance to flow, e.g., the formation of cracks (Fig. 6). It should be noted that the addition of hydraulic pulses only marginally affects the long-term time averaged water flow rates, as injection occurs intermittently and over short time intervals. The long-term time averaged pumping ( $60 \mathrm{~mL} \mathrm{~h}^{-1}$ at constant flow, $84 \mathrm{~mL} \mathrm{~h}^{-1}$ when adding pressure pulses at 2-min intervals) as well as the source pressures measured during the intermittent hydraulic pulses that formed cracks (approx. $17.5 \mathrm{~cm}$ ) are well within the range reported for lugworms, with a normal pumping rate of $90 \mathrm{~mL}$ $\mathrm{min}^{-1}$ and normal operating pressure of $5 \mathrm{~cm} \mathrm{H}_{2} \mathrm{O}$ and a maximal pressure of $20 \mathrm{~cm} \mathrm{H}_{2} \mathrm{O}$ (Riisgård et al. 1996).

In conclusion, the results presented demonstrate that the Robolug irrigation system can mimic the full range of porewater pressure waveforms, porewater flow patterns, and geochemical dynamics associated with bio-hydraulic activities of live lugworms. Robolug-mimicked behaviors are consistent with (1) interpretation of previously obtained data with pressure sensors and oxygen optodes in sediments with live Arenicola marina (Volkenborn et al. 2010), (2) models of bioadvective porewater fluxes (Wethey et al. 2008), and (3) energy requirements of the 'lugworm pump' (Riisgård et al. 1996; Meysman et al. 2005).

\section{Comments and recommendations}

The artificial irrigation system described here is the first mechanical mimic that allows imitation of complex hydraulic behaviors of bioirrigating infauna. By injecting water at set locales with realistic magnitude, duration, chronology and repetition, complex bioirrigation sequences can be reproduced accurately, repeatedly, and over extended periods of time. The irrigation water can be modified (e.g., de-oxygenated, enriched with tracers, organic matter, or microbial inhibitors), allowing experimental treatments that could potentially be harmful for live animals. Furthermore, the mechanical components of the system, such as roller arrangement, tubing sizes, or injection speed, can be adjusted depending on the target species. Thus, the system offers a great deal of flexibility for experimental examination of the effects of bioirrigating infauna on sedimentary processes, both in the laboratory and in the field.

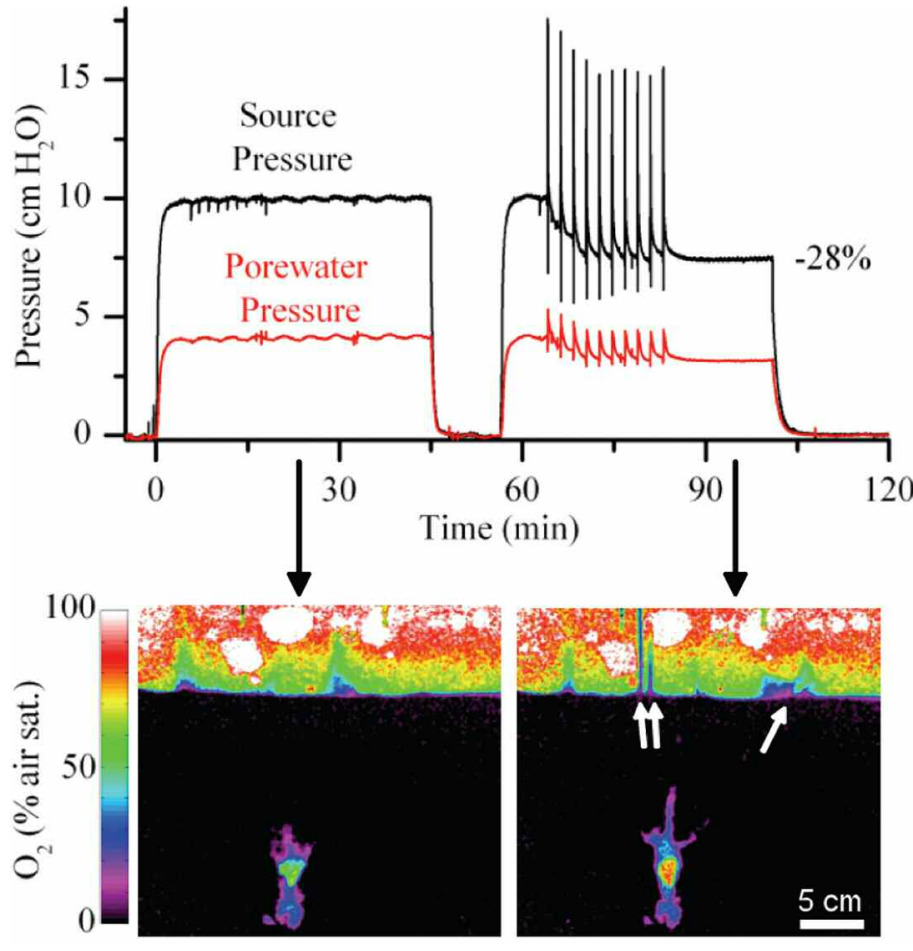

Fig. 6. Pressure waveforms $(A)$ and oxygen images (B-C) indicative of porewater flow patterns associated with the formation of sedimentary cracks induced by hydraulic pulses. Water was injected into the sediment at a constant rate of $1 \mathrm{~mL} \mathrm{~min}-1$ during time intervals $0-15 \mathrm{~min}$ and 56-101 min. At time $64 \mathrm{~min}$ and in 2-min intervals, 10 water packets of $0.8 \mathrm{~mL}$ were additionally injected over $6 \mathrm{~s}$ intervals. Formation of a new crack was indicated by a $23 \%$ and $28 \%$ reduction in the porewater and source pressures, respectively, as well as in the appearance of a jet-like outflow of anoxic porewater through the sediment-water interface (indicated by arrows in the oxygen image). Note that due to injection of airsaturated water, the oxygen concentrations in the deep sediment are higher than those typically observed with live worms.

In a strict sense, the Robolug allows the study of specific effects of bio-advection only, i.e., porewater transport induced by bio-hydraulic activities of animals. As such, the system has its limits. First, it cannot account for particle movements induced by the animal, e.g., due to sediment reworking or feeding. Second, in its present form, the system does not account for potential water flow and consequent pressure release through a burrow wall that is not perfectly lined. However, recent modeling studies indicated that advective transport across the burrow wall is limited for lugworms (Meysman et al. 2005) and porewater pressure fields in the presence of lugworms can adequately be described even if the burrow is omitted (Meysman et al. 2005; 2006; Wethey et al. 2008). Nevertheless, if necessary, partial pressure release could be accounted for by the use of porous tubing. Third, by pumping water through gas-impermeable tubing, oxygen loss due to animal respiration and sedimentary oxygen consumption at the burrow wall is neglected. However, these and any other effects of the animal (e.g., infaunal exudates or metabolites) 
and the burrow wall on the chemical composition of the injected water can easily be accounted for by the appropriate modification of the pumped water. Budget calculations suggest that roughly $50 \%$ of the oxygen is consumed by the animal, whereas $23 \%$ is consumed biogeochemically at the burrow wall mediated by diffusive oxygen uptake, and $28 \%$ is consumed biogeochemically in the advective zone surrounding the injection pocket (Timmermann et al. 2006). The relative contribution to the overall oxygen consumption may vary considerably among sediment types, and the oxygen concentration of the water that is injected into the sediment may vary between $5 \%$ and $80 \%$ air saturation (Volkenborn et al. 2010). During the assessment of Robolug, we used oxygen effectively as a reactive tracer to visualize porewater flow field patterns. Thus, the oxygen concentrations and the scale of impact presented in this study need to be interpreted with caution. For detailed studies of biogeochemical response to oxygen supply in the advective zone, the oxygen concentration of the irrigated water should be adjusted accordingly.

Despite its limitations, the Robolug has a number of interesting applications in diverse fields such as biogeochemistry, benthic ecology, biomechanics, or bioenergetics. Of particular interest is the study of rapid redox oscillations induced by bioadvection. As shown by Volkenborn et al. (2010) and suggested by the models and observations of Wethey et al. (2008), hydraulic activities of lugworms result in oscillatory redox conditions in the sediment on the scale of seconds to minutes. As this is approximately the scale on which microorganisms respond to altered chemical conditions (Cypionka 1995; Stocker et al. 2008), it is very likely that the transient availability of metabolites and electron acceptors (e.g., oxygen) will affect microbial activity. Redox oscillations on the scale of hours to days have been found to increase organic remineralization (Aller 1994; Sun et al. 2002; Franke et al. 2006). Shortterm fluctuations between oxic and anoxic conditions also prevent the completion of certain metabolic pathways, causing the release of chemical intermediates (e.g., $\mathrm{NO}$ or $\mathrm{N}_{2} \mathrm{O}$ : Schreiber et al. 2009; Stief et al. 2009). Recruitment of many benthic species is affected by a variety of geochemical cues at the sediment-water interface, and the decision to burrow at a given locale is made within $30 \mathrm{~s}$ after the first contact with the sediment surface and is often based on the chemical signature of the sediment (Woodin et al. 1995, 1998; Marinelli and Woodin 2002). Thus, the time scale on which hydraulic activity affects the distribution of porewater solutes and drives benthic-pelagic exchange processes is likely to have manifold impacts on benthic ecosystem functioning. The Robolug has performance characteristics that allow experimental analysis of these kinds of questions at biologically relevant spatial and temporal scales.

Another attractive application of the Robolug is the study of energy requirements associated with bio-hydraulic activities of benthic infauna. By detecting the source pressure during controlled hydraulic activity, the energy involved in the trans- port of interstitial water by the different activities can be directly measured. Furthermore, by applying various types of hydraulic pulses, mechanisms behind sediment cracking by pulsed water injection can be revealed. As shown in this study, the generally observed reduction in source pressure after crack formation implies that the mechanical work required to pump the same amount of water per unit time is lower than it was before the crack was formed. This suggests that sediment cracking may be beneficial for the lugworm in that a shortterm higher-energy investment to form cracks yields longterm benefits in the form of decreased energy requirements for peristaltic pumping. Considering that the advective porewater flow field generated by a single lugworm reaches centimeters to decimeters around the animal (Meysman et al. 2005; Wethey et al. 2008), the impact of these benefits may be extrapolated further, including neighboring lugworms as well as other organisms that rely on the supply of substrates by advection. Experiments studying such complex interactions can easily be designed and carried out using the Robolug.

\section{Author contributions}

SAW conceived the idea and with GYM built the prototype. NV and GYM carried out the experiments; LP wrote the optode data capture and analysis software; UH and LP wrote the optode camera control software; DSW built the pressure sensor system; DSW and LP wrote the pressure analysis software. NV, GYM, SAW, LP, DSW, and CRL contributed to the experimental design, data analysis and writing, which was led by GYM and NV.

\section{References}

Aller, R. C. 1980. Quantifying solute distributions in the bioturbated zone of marine-sediments by defining an average micro-environment. Geochim. Cosmochim. Acta 44:19551965 [doi:10.1016/0016-7037(80)90195-7].

- 1994. Bioturbation and remineralization of sedimentary organic matter: effects of redox oscillation. Chem. Geol. 114:331-345 [doi:10.1016/0009-2541(94)90062-0]. 2001. Transport and reactions in the bioirrigated zone, p. 269-301. In B. P. Boudreau and B. B. Jørgensen [eds.], The benthic boundary layer: transport processes and biogeochemistry. Oxford.

Boudreau, B. P. 1997. Diagenetic models and their implementation: modelling transport and reactions in aquatic sediments. Springer-Verlag.

— continuous biological irrigation. J. Mar. Res. 52:947-968 [doi:10.1357/0022240943076902].

Cypionka, H. 1995. Solute transport and cell energetics, p. 151-184. In L. L. Barton [ed.], Sulfate-reducing bacteria. Plenum.

Dorgan, K. M., P. A. Jumars, B. D. Johnson, and B. P. Boudreau. 2006. Macrofaunal burrowing: the medium is the message. Oceanogr. Mar. Biol. 44:85-121.

Franke, U., L. Polerecky, E. Precht, and M. Huettel. 2006. Wave 
tank study of particulate organic matter degradation in permeable sediments. Limnol. Oceanogr. 51:1084-1096 [doi:10.4319/lo.2006.51.2.1084].

Gao, H., and others. 2010. Aerobic denitrification in permeable Wadden Sea sediments. ISME J. 4:417-426 [doi:10.1038/ismej.2009.127].

Glud, R. N., N. B. Ramsing, J. K. Gundersen, and I. Klimant. 1996. Planar optodes: a new tool for fine scale measurements of two-dimensional $\mathrm{O}_{2}$ distribution in benthic communities. Mar. Ecol. Prog. Ser. 140:217-226 [doi:10.3354/ meps140217].

Holst, G., and B. Grunwald. 2001. Luminescence lifetime imaging with transparent oxygen optodes. Sensors Actuat. B 74:78-90 [doi:10.1016/S0925-4005(00)00715-2].

Huettel, M., and G. Gust. 1992. Impact of bioroughness on interfacial solute exchange in permeable sediments. Mar. Ecol. Prog. Ser. 89:253-267 [doi:10.3354/meps089253].

Jahnke, R. A. 2001. Constraining organic matter cycling with benthic fluxes, p. 302-319. In B. P. Boudreau and B. B. Jørgensen [eds.], The benthic boundary layer: transport processes and biogeochemistry. Oxford.

Kristensen, E. 1988. Benthic fauna and biogeochemical processes in marine sediments: microbial activities and fluxes, p. 275-299. In T. H. Blackburn and J. Sørensen [eds.], Nitrogen cycling in coastal marine environments. Wiley.

- 2001. Impact of polychaetes (Nereis spp. and Arenicola marina) on carbon biogeochemistry in coastal marine sediments. Geochem. Trans. 12:92-103 [doi:10.1186/14674866-2-92].

Krueger, F. 1964. Experiments concerning the dependence of respiration of Arenicola marina (Annelides Polychaeta) on size and temperature. Helgol. Wiss. Meeresunters. 10:38-63.

Kühl, M., and L. Polerecky. 2008. Functional and structural imaging of phototrophic microbial communities and symbioses. Aquat. Microb. Ecol. 53:99-118 [doi:10.3354/ame01224].

Lohrer, A. M., S. F. Thrush, and M. M. Gibbs. 2004. Bioturbators enhance ecosystem function through complex biogeochemical interactions. Nature 431:1092-1095 [doi:10.1038/ nature03042].

Marinelli, R. L. 1994. Effects of burrow ventilation on activities of a terebellid polychaete and silicate removal from sediment pore waters. Limnol. Oceanogr. 39:303-317 [doi:10.4319/lo.1994.39.2.0303].

_ linkages between infaunal recruitment, disturbance, and sediment surface chemistry. Limnol. Oceanogr. 47:221-229 [doi:10.4319/lo.2002.47.1.0221].

Mermillod-Blondin, F., R. Rosenberg, F. François-Carcaillet, K. Norling, and L. Mauclaire. 2004. Influence of bioturbation by three benthic infaunal species on microbial communities and biogeochemical processes in marine sediment. Aquat. Microb. Sci. 36:271-284 [doi:10.3354/ame036271].

— impact of bioturbation on biogeochemical processes in marine and freshwater benthic habitats. Aquat. Sci. 68:434442 [doi:10.1007/s00027-006-0858-x].

Meysman, F. J. R., O. S. Galaktionov, and J. J. Middelburg. 2005. Sediment irrigation patterns induced by Arenicola marina burrow ventilation. Mar. Ecol. Prog. Ser. 303:195212 [doi:10.3354/meps303195].

- — B. Gribsholt, and J. J. Middelburg. 2006. Bioirrigation in permeable sediments: advective pore-water transport induced by burrow ventilation. Limnol. Oceanogr. 51:142-156 [doi:10.4319/lo.2006.51.1.0142].

- , P. L. M. Cook, F. Janssen, M. Huettel, and J. J. Middelburg. 2007. Quantifying biologically and physically induced flow and tracer dynamics in permeable sediments. Biogeosciences 4:627-646 [doi:10.5194/bg-4-627-2007].

Na, T., B. Gribsholt, O. S. Galaktionov, T. Lee, and F. J. R. Meysman. 2008. Influence of advective bio-irrigation on carbon and nitrogen cycling in sandy sediments. J. Mar. Res. 66:691-722 [doi:10.1357/002224008787536826].

Polerecky, L., N. Volkenborn, and P. Stief. 2006. High temporal resolution oxygen imaging in bioirrigated sediments. Environ. Sci. Technol. 40:5763-5769 [doi:10.1021/
[do es0604941].

Precht, E., U. Franke, L. Polerecky, and M. Huettel. 2004. Oxygen dynamics in permeable sediments with wave-driven pore water exchange. Limnol. Oceanogr. 49:693-705 [doi:10.4319/lo.2004.49.3.0693].

Riisgård, H. U., I. Berntsen, and B. Tarp. 1996. The lugworm (Arenicola marina) pump: characteristics, modelling and energy cost. Mar. Ecol. Prog. Ser. 138:149-156 [doi:10.3354/ meps138149].

Sandwell, D. R., C. A. Pilditch, and A. M. Lohrer. 2009. Density dependent effects of an infaunal suspension-feeding bivalve (Austrovenus stutchburyi) on sandflat nutrient fluxes and microphytobenthic productivity. J. Exp. Mar. Biol. Ecol 373:16-25 [doi:10.1016/j.jembe.2009.02.015].

Schreiber, F., B. Loeffler, L. Polerecky, M. M. Kuypers, and D. de Beer. 2009. Mechanisms of transient nitric oxide and nitrous oxide production in a complex biofilm. ISME J. 3:1301-1313 [doi:10.1038/ismej.2009.55].

Stief, P., M. Poulsen, L. P. Nielsen, H. Brix, and A. Schramm. 2009. Nitrous oxide emission by aquatic macrofauna. Proc. Natl. Acad. Sci. U.S.A. 106:4296-4300 [doi:10.1073/pnas.08 08228106].

Stocker, R., J. R. Seymour, A. Samadani, D. E. Hunt, and M. F. Polz. 2008. Rapid chemotactic response enables marine bacteria to exploit ephemeral microscale nutrient patches. Proc. Natl. Acad. Sci. U.S.A. 105:4209-4214 [doi:10.1073/pnas.0709765105].

Sun, M. Y., R. C. Aller, C. Lee, and S. G. Wakeham. 2002. Effects of oxygen and redox oscillation on degradation of cell-associated lipids in surficial marine sediments. Geochim. Cosmochim. Acta 66:2003-2012 [doi:10.1016/S0016-7037(02)00830-X]. 
Thrush, S. F., J. E. Hewitt, M. Gibbs, C. Lundquist, and A. Norkko. 2006. Functional role of large organisms in intertidal communities: community effects and ecosystem function. Ecosystems 9:1029-1040 [doi:10.1007/s10021-0050068-8].

Timmermann, K., G. T. Banta, and R. N. Glud. 2006. Linking Arenicola marina irrigation behavior to oxygen transport and dynamics in sandy sediments. J. Mar. Res. 64:915-938 [doi:10.1357/002224006779698378].

Volkenborn, N., S. I. C. Hedtkamp, J. E. E. van Beusekom, and K. Reise. 2007a. Effects of bioturbation and bioirrigation by lugworms (Arenicola marina) on physical and chemical sediment properties and implications for intertidal habitat succession. Estuar. Coast. Shelf Sci. 74:331-343 [doi:10.1016/ j.ecss.2007.05.001].

- L. Polerecky, S. I. C. Hedtkamp, J. E. E. van Beusekom, and D. de Beer. 2007b. Bioturbation and bioirrigation extend the open exchange regions in permeable sediments. Limnol. Oceanogr. 52:1898-1909 [doi:10.4319/lo.2007.52. 5.1898].

, D. S. Wethey, and S. A. Woodin. 2010. Oscillatory porewater bioadvection in marine sediments induced by hydraulic activities of Arenicola marina. Limnol. Oceanogr. 55:1231-1247 [doi:10.4319/lo.2010.55.3.1231].

Waldbusser, G. G., and R. L. Marinelli. 2006. Macrofaunal modification of porewater advection: role of species function, species interaction, and kinetics. Mar. Ecol. Prog. Ser. 311:217-231 [doi:10.3354/meps311217].

Wells, G. P. 1945. The mode of life of Arenicola marina L. J. Mar. Biol. Assoc. U.K. 26:170-207 [doi:10.1017/S002531540001 1826].
1953. Defecation in relation to the spontaneous activity cycles of Arenicola marina L. J. Mar. Biol. Assoc. U.K. 32:51-63 [doi:10.1017/S0025315400011425].

Wenzhöfer, F., and R. N. Glud. 2004. Small-scale spatial and temporal variability in coastal benthic $\mathrm{O}_{2}$ dynamics: effects of fauna activity. Limnol. Oceanogr. 49:1471-1481 [doi:10.4319/lo.2004.49.5.1471].

Wethey, D. S., and S. A. Woodin. 2005. Infaunal hydraulics generate porewater pressure signals. Biol. Bull. 209:139-145 [doi:10.2307/3593131].

—, S. A. Woodin, N. Volkenborn, and K. Reise. 2008. Porewater advection by hydraulic activities of lugworms, Arenicola marina: a field, laboratory and modeling study. J. Mar. Res. 66:255-273 [doi:10.1357/002224008785837121].

Woodin, S. A., S. M. Lindsay, and D. S. Wethey. 1995. Processspecific recruitment cues in marine sedimentary systems. Biol. Bull. 189:49-58 [doi:10.2307/1542201].

—, R. L. Marinelli, and S. M. Lindsay. 1998. Process-specific cues for recruitment in sedimentary environments: geochemical signals? J. Mar. Res. 56:535-558 [doi:10.1357/002224098321822410].

, and D. S. Wethey. 2009. Arenicolid behaviors: similarity of Arenicola marina and Abarenicola pacifica. ZooSymposia 2:447-456.

, D. S. Wethey, and N. Volkenborn. 2010. Infaunal hydraulic ecosystem engineers: cast of characters and impacts. Int. Comp. Biol. 50:176-187.

Submitted 1 February 2010 Revised 9 November 2010 Accepted 14 January 2011 